\title{
Incidence of early pregnancy bleeding in the Eastern region of Saudi Arabia
}

\section{Wafaa Hassan $^{1}$, Munir Abu-Helalah ${ }^{2}$, Abdul Salam², Abdelmonim Elhakim ${ }^{3}$, Honida Bayazeed ${ }^{1}$, Shahid Latif ${ }^{4}$, Rifat Rehmani ${ }^{3}$}

\author{
${ }^{1}$ Department of Obstetrics and Gynecology, King Abdulaziz Hospital, NGHA-Alhassa, KSA \\ ${ }^{2}$ King Abdullah International Medical Research Center, National Guard Health Affairs Alhassa KSA \\ ${ }^{3}$ Department of Emergency Medicine, Staff Physician King Abdulaziz Hospital, NGHA-Alhassa, KSA \\ ${ }^{4}$ Department of Obstetrics and Gynecology, Prince Mohammed Bin Abdulaziz Hospital, KSA
}

Received: 28 January 2016

Accepted: 01 March 2016

\section{* Correspondence:}

Dr. Wafaa Hassan,

E-mail: hassanw_19@hotmail.com

Copyright: (C) the author(s), publisher and licensee Medip Academy. This is an open-access article distributed under the terms of the Creative Commons Attribution Non-Commercial License, which permits unrestricted non-commercial use, distribution, and reproduction in any medium, provided the original work is properly cited.

\begin{abstract}
Background: Early pregnancy bleeding (EPB) is defined as bleeding within the first 20 weeks of gestation. Women who present with bleeding in early pregnancy have $30-50 \%$ probability of having a failed pregnancy. Recent US statistics report that it accounts for $1.6 \%$ of all ED visits. Although first-trimester vaginal bleeding is an alarming symptom, there is limited published literature on its incidence, timing, and risk factors and there is no published data from the KSA.

Methods: This retrospective cohort study included pregnant women who attended their first antenatal visit between August 2011 and May 2012.

Results: The number of participants was 724 women who attended the antenatal clinic for first pregnancy visit. $37.85 \%$ of them (274) of developed first trimester vaginal bleeding. $62 \%$ experienced mild bleeding, $15.4 \%$ had moderate bleeding, $13.9 \%$ had spotting, while $4.9 \%$ of had severe bleeding. The incidence of threatened miscarriage was the highest $(11.5 \%)$ followed by incomplete miscarriage $(8.8 \%)$ and missed carriage $(7.7 \%)$. The incidence of molar pregnancy in our study of $0.55 \%$ was very high.

Conclusions: The incidence of first trimester vaginal bleeding is high in our center when compared with figures from published literature. The incidence of threatened miscarriage is low, while the incidence of complete or incomplete miscarriage is relatively high. Similar to other reports from Asia, the incidence of molar pregnancy was very high. Further research is recommended to justify the detected high first trimester vaginal bleeding rates and to identify potentials of prevention or improvement of the outcomes of bleeding.
\end{abstract}

Keywords: EPB, Vaginal bleeding, First trimester, Saudi Arabia, Abortion

\section{INTRODUCTION}

Early pregnancy bleeding (EPB) is defined as bleeding within the first 20 weeks of gestation. Women who present with bleeding in early pregnancy have 30-50\% probability of having a failed pregnancy, $2 \%$ chance of having an ectopic pregnancy and $0.1 \%$ chance of having a molar pregnancy. ${ }^{1,2}$ Recent US statistics report that it accounts for $1.6 \%$ of all ED visits. ${ }^{3}$ Although firsttrimester vaginal bleeding is an alarming symptom, there is limited published literature on its prevalence, timing, and risk factors. ${ }^{4-6}$ Results of studies on prevalence of early pregnancy bleeding are imprecise and range from 7 to $24 \%$. $^{7-10}$ This wide range could be attributed to differences in study design.

There are a wide range of clinical presentations of vaginal bleeding ranging from the classic collapsed patient with a haemoperitoneum, to vaginal spotting. Pregnancy may still be viable despite quite a heavy loss. However an 
ectopic pregnancy is not usually associated with excessive vaginal bleeding. ${ }^{12}$

There is no clear figure about incidence of first trimester vaginal bleeding in Saudi Arabia or the region. The only published figures are on prevalence of ectopic pregnancy in Saudi Arabia with prevalence range between $0.58 \%$ and $1.13 \% .{ }^{13-15}$ We proposed a retrospective cohort study to measure the incidence of first trimester vaginal bleeding and incidence of common causes of this bleeding and study the characteristics of the first trimester bleeding by diagnosis.

\section{METHODS}

This retrospective cohort study included pregnant women who attended their first antenatal visit between August 2011 and May 2012. Gestational age was calculated based on self-reported last menstrual period (LMP). If self-reported LMP was unavailable, ultrasound-based gestational age was used. Pregnancy was verified by ultrasound and pregnancy test. Miscarriage was defined as loss of a recognized pregnancy prior to twenty completed weeks of gestation.

Ethical approval was obtained from King Abdullah International Medical Research Center at the National Guard Health Affairs.

The data has been retrieved from the computer, all patients who had complained of vaginal bleeding in early pregnancy less than 20 weeks either admitted or discharged.

We applied the definitions and subcategories of miscarriages described by Anderson A. and colleagues. ${ }^{16}$

Medical records of pregnant women with history of first trimester vaginal bleeding were reviewed. These records, mainly visits to the emergency department or to the outpatients' clinics, were reviewed for the total number of bleeding episodes experienced during the first trimester and detailed information about the timing, heaviness, duration, and pain.

If bleeding stopped for at least two days and then started again, this was considered two separate episodes of bleeding. Duration was reported in days. Heaviness was defined according to the heaviest bleeding in an episode, and was compared to heaviness of usual menses. A 'spotting' episode was only noticed when wiping, a 'light bleeding' episode was defined as having the heaviest day(s) of flow being lighter than the heavy flow of a usual menstrual period, and a heavy bleeding episode was defined as having the heaviest day(s) of flow as heavy or heavier than the heavy flow of a usual menstrual period. If participants reported bleeding-associated pain, they were asked to characterize the pain as mild, moderate, or severe.
Data collected at the first trimester interview included demographic factors (age, education, pre-pregnancy body mass index, usual menstrual cycle length in days, maternal morbidities (reproductive tract infections during pregnancy and diabetes), and prior obstetric history (parity, gravidity, history of miscarriage, induced abortion for medical reasons, or preterm birth).

Abdominal pain may be severe as a pregnancy is miscarrying, or in a ruptured ectopic pregnancy. Specific inquiry should be made about shoulder tip pain. A history of vaginal discharge, pelvic pain, dyspareunia, or fever may suggest pelvic inflammatory disease which can also cause irregular vaginal bleeding.

Past gynaecological history included previous surgery, history of pelvic infection, infertility investigations, and any recent treatment, for example cervical diathermy. Past Obstetric History included previous miscarriages, ectopic, and viable pregnancies. Medical history included the presence of other comorbidities, bleeding disorders such as von Will brand's disease. Drug history was retrieved to identify drug that could increase risk of bleeding like Warfarin and Aspirin.

\section{Physical examination}

Cardiovascular status-evidence of shock was also assessed. The blood pressure may remain normal despite a large blood loss; tachycardia is usually the first indicator of excessive loss.

Pelvic examination: a complete pelvic examination should be performed. The speculum examination is used to confirm that the uterus is the source of bleeding (rather than a cervical or vaginal lesion) and to assess the volume of bleeding. The most important component of the examination is to determine whether the cervix is dilated and whether products of conception are visible at the cervix or in the vagina. These features are used to classify the status of the spontaneous miscarriage, which impacts management.

A bimanual pelvic examination is performed to determine uterine size; an abdominal examination may also be useful when gestational age is greater than 12 weeks. In normal pregnancy, the size of the uterus should be consistent with gestational age. The uterus may be enlarged due to multiple gestations or the presence of uterine leiomyomas. A small for gestational age uterus raises suspicion of a spontaneous miscarriage.

A purulent cervical discharge or uterine tenderness suggests a possible septic abortion, which also should be suspected in women who appear ill or are febrile. ${ }^{15}$

Pelvic ultrasonography and fetal Doppler ultrasound: If more than 14 weeks it may be possible to hear the fetal heart with a Doppler ultrasound. 


\section{Pelvic ultrasonography}

It is the most useful test in the diagnostic evaluation of women with suspected spontaneous miscarriage. ${ }^{17}$ The most important finding is fetal cardiac activity, which is typically first detected at 5.5 to 6 weeks. Other important findings are the size and contour of the gestational sac, the presence of a yolk sac, and the fetal heart rate. In general, these early pregnancy sonograms are performed transvaginally, as the gestational sac and its contents are best evaluated in early gestation through a transvaginal approach.

\section{Laboratory evaluation}

Human chorionic gonadotropin - A serum human chorionic gonadotropin (hCG) should be taken. A single hCG concentration is not informative in the diagnosis of spontaneous miscarriage, but a baseline is useful if the ultrasound findings are non-diagnostic or if ectopic pregnancy is suspected. In such cases, serial hCG measurement may be necessary.

In failed pregnancies, a decline in serum hCG is usually apparent based upon two measurements at least two days apart.

Blood type and antibody screen - A Rh(D) typing and antibody screen should be taken if not previously performed during the current pregnancy. Women with bleeding in pregnancy who are $\mathrm{Rh}(\mathrm{D})$-negative should be given anti-D immune globulin according to the guidline. $^{15}$

\section{Full blood count}

This should be checked in every case as there are frequent surprises when women who appear haemodynamically stable are found to be profoundly anaemic. A raised white cell count may suggest an infection, although the white count is slightly higher in a normal pregnancy.

Low platelets may also indicate a coagulation problem. A full coagulation screen may be necessary with severe haemorrhage, or if a septic abortion is suspected because of the risk of disseminated intravascular coagulation. ${ }^{14}$

\section{Sample size}

The primary objective of the study was to measure the prevalence of first trimester vaginal bleeding. It has been reported that rates of first trimester vaginal bleeding are between 7 to $27 \%$,[18] therefore a total sample size of 724 women was needed to produce a two sided $99 \%$ confidence interval (22.8\% to $31.5 \%)$, using Binomial distribution. $^{19}$

\section{Statistical methods}

Descriptive results were presented as mean \pm standard deviation (In case the data is normally distributed), or median with inter-quartile range (in case if data are not normally distributed) for all quantitative variables. Number (percentage) was reported for all qualitative variables. A binomial distribution was used to measure the incidence of Vaginal bleeding disorders within a $95 \%$ confidence interval.

All the demographics and clinical examination characteristics were compared by final diagnosis (threatened, missed, incomplete, ectopic, and others miscarriages) to assess the statistical association. ANOVA or Kruskil-Wallis test were used to compare all of the quantitative variables (e.g. age) and Pearson ChiSquare test or Fisher exact were used to compare all the qualitative variables (e.g. gender) by final diagnosis whenever appropriate. Statistical significance was established when $\mathrm{p}<0.05$ (two-tailed). All statistical analyses were performed using SPSS (Statistical Package for Social Sciences version 20.0).

\section{RESULTS}

This study was based on cohort of 724 Women who attended the antenatal clinic for first pregnancy visit between 1 August 2011 and 1 May 2012 at the National Guard Health Affairs, Alhassa, KSA. 37.85\% of them (274) of them developed first trimester vaginal bleeding. All of them were seen at the Accidents and emergency department. Analysis of the data of these 274 patients will be presented in this section. Baseline characteristics for all participants with first trimester vaginal bleeding are shown in table 1 by final diagnosis. The median age was 31 years with Inter quartile (IQ) range of 26 to 37 years. The mean gestational age was 10.2 with standard deviation (SD) of (3.6). Patients with ectopic pregnancy presented at an earlier gestation than the remaining participants (mean: 6.4 \pm SD (1.2), $\mathrm{P}<0.001$ ). The median gravida was 4 and the median parity was 2 . The median history of miscarriage was 0 with a range from 0 to 10 . $72.5 \%$ of the patients had mild abdominal pain, $6.8 \%$ suffered from moderate to severe pain, while $20.8 \%$ did not have abdominal pain. Moderate to severe pain was present in $2.5 \%$ of patients with threatened miscarriage, $13.1 \%$ of patients with incomplete miscarriage and $23.5 \%$ of patients with ectopic pregnancy (Table 1).

Comparison between patients by final diagnosis, as shown in table 1 , shows that patients with ectopic

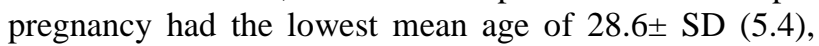
while patients with missed miscarriage had the highest mean age of $33.2 \pm \mathrm{SD}$ (7.2). It also reveals that there was statistically significant difference by final diagnosis in number of previous pregnancies $(<0.001)$ but not in number of previous miscarriages $(0.163)$. The highest median parity was for missed miscarriage (3.5), while the lowest was for ectopic pregnancy (1) (Table 1). 
Table 1: Baseline characteristics $(n=274)$.

\begin{tabular}{|c|c|c|c|c|c|c|c|}
\hline \multirow[b]{2}{*}{ Factor } & \multirow[b]{2}{*}{$\underset{(n=274)}{\text { Overall }}$} & \multicolumn{5}{|c|}{ Diagnoses } & \multirow[b]{2}{*}{ P-value } \\
\hline & & $\begin{array}{l}\text { Threatened } \\
(\mathrm{n}=83)\end{array}$ & $\begin{array}{l}\text { Missed mis- } \\
\text { carriage } \\
(\mathrm{n}=62)\end{array}$ & $\begin{array}{l}\text { Incomplete } \\
\text { mis-carriage } \\
(n=64)\end{array}$ & $\begin{array}{l}\text { Ectopic } \\
(n=17)\end{array}$ & $\begin{array}{l}\text { Others } \\
(n=48)\end{array}$ & \\
\hline Age in Years ${ }^{(\mathrm{n}=274)}$ & $31.7 \pm 07.2$ & $31.2 \pm 6.8$ & $33.2 \pm 7.2$ & $33.1 \pm 7.8$ & $28.6 \pm 5.4$ & $29.9 \pm 7.1$ & $0.023^{\dagger}$ \\
\hline Gravida $^{(\mathrm{n}=274)}$ & $4(1-13)$ & $3(1-13)$ & $6(1-12)$ & $5(1-13)$ & $3.5(2-6)$ & $3(1-13)$ & $0.006 *$ \\
\hline Parity $(\mathrm{n}=274)$ & $2(0-12)$ & $2(0-10)$ & $3.5(0-10)$ & $3(0-12)$ & $1(0-3)$ & $1(0-11)$ & $<0.001 *$ \\
\hline Miscarriage $^{(\mathrm{n}=274)}$ & $0(0-10)$ & $0(0-9)$ & $0(0-7)$ & $1(0-10)$ & $1(0-4)$ & $0(0-9)$ & $0.163 *$ \\
\hline \multicolumn{8}{|l|}{ Abdominal pain ${ }^{(\mathrm{n}=265)}$} \\
\hline No & $55(20.8 \%)$ & $08(09.9 \%)$ & $20(33.3 \%)$ & $09(14.8 \%)$ & $04(23.5 \%)$ & $14(30.4 \%)$ & \multirow{3}{*}{$<0.001$} \\
\hline Mild & $192(72.5 \%)$ & $71(87.7 \%)$ & $40(66.7 \%)$ & $44(72.1 \%)$ & $09(52.9 \%)$ & $28(60.9 \%)$ & \\
\hline Moderate-Severe & $18(06.8 \%)$ & $02(02.5 \%)$ & 0 & $08(13.1 \%)$ & $04(23.5 \%)$ & $04(08.7 \%)$ & \\
\hline $\begin{array}{l}\text { Abdominal duration } \\
\text { (days) }^{(\mathrm{n}=211)}\end{array}$ & $1(0-7)$ & $1(0-7)$ & $0.5(0-7)$ & $1(0-7)$ & $1.5(0-5)$ & $1(0-3)$ & $0.072 *$ \\
\hline \multicolumn{8}{|l|}{ Syncope $\mathrm{e}^{(\mathrm{n}=273)}$} \\
\hline No & $269(98.5 \%)$ & $82(98.8 \%)$ & $61(100 \%)$ & $62(96.9 \%)$ & $17(100 \%)$ & $47(97.9 \%)$ & \multirow[t]{2}{*}{$0.694^{\psi}$} \\
\hline Yes & $04(01.5 \%)$ & $01(01.2 \%)$ & 0 & $02(03.1 \%)$ & 0 & $01(02.1 \%)$ & \\
\hline \multicolumn{8}{|l|}{ Shoulder Tips ${ }^{(\mathrm{n}=274)}$} \\
\hline No & $274(100 \%)$ & $83(100 \%)$ & $62(100 \%)$ & $64(100 \%)$ & $17(100 \%)$ & $48(100 \%)$ & \\
\hline Yes & 0 & 0 & 0 & 0 & 0 & 0 & \\
\hline Gestational Age $^{(\mathrm{n}=271)}$ & $10.2 \pm 03.6$ & $10.3 \pm 3.6$ & $11.6 \pm 3.4$ & $9.8 \pm 3.4$ & $6.4 \pm 1.2$ & $9.9 \pm 3.8$ & $<0.001^{\dagger}$ \\
\hline
\end{tabular}

Table 2: Clinical examination outcomes for patients with first trimester vaginal bleeding.

\begin{tabular}{|c|c|c|c|c|c|c|c|}
\hline \multirow[b]{2}{*}{ Factor } & \multirow[b]{2}{*}{$\begin{array}{l}\text { Overall } \\
(\mathrm{n}=274)\end{array}$} & \multicolumn{5}{|c|}{ Diagnoses } & \multirow[b]{2}{*}{$\begin{array}{l}\text { P- } \\
\text { value }\end{array}$} \\
\hline & & $\begin{array}{l}\text { Threatened } \\
(\mathrm{n}=83)\end{array}$ & $\begin{array}{l}\text { Missed mis- } \\
\text { carriage } \\
(\mathrm{n}=62)\end{array}$ & $\begin{array}{l}\text { Incomplete } \\
\text { mis-carriage } \\
(n=64)\end{array}$ & $\begin{array}{l}\text { Ectopic } \\
(\mathrm{n}=17)\end{array}$ & $\begin{array}{l}\text { Others } \\
(\mathrm{n}=48)\end{array}$ & \\
\hline \multicolumn{8}{|c|}{ Previous pelvic surgery ${ }^{(\mathrm{n}=272)}$} \\
\hline No & $142(52.2 \%)$ & $47(56.6 \%)$ & $29(47.5 \%)$ & $30(47.6 \%)$ & $08(47.1 \%)$ & $28(58.3 \%)$ & \multirow{2}{*}{$0.624^{\psi}$} \\
\hline Yes & $130(47.4 \%)$ & $36(43.4 \%)$ & $32(52.5 \%)$ & $33(52.4 \%)$ & $09(52.9 \%)$ & $20(41.7 \%)$ & \\
\hline \multicolumn{8}{|c|}{ History of infertility ${ }^{(\mathrm{n}=274)}$} \\
\hline No & $254(92.7 \%)$ & $70(84.3 \%)$ & $61(98.4 \%)$ & $63(98.4 \%)$ & $15(88.2 \%)$ & $45(93.8 \%)$ & \multirow{2}{*}{0.003} \\
\hline Yes & $20(07.3 \%)$ & $13(15.7 \%)$ & $01(01.6 \%)$ & $01(01.6 \%)$ & $02(11.8 \%)$ & $03(06.3 \%)$ & \\
\hline \multicolumn{8}{|c|}{ Recent treatment for gyne ${ }^{(\mathrm{n}=274)}$} \\
\hline No & $259(94.5 \%)$ & $70(84.3 \%)$ & $61(98.4 \%)$ & $64(100 \%)$ & $17(100 \%)$ & $47(97.9 \%)$ & \multirow{2}{*}{$<0.001$} \\
\hline Yes & $15(05.5 \%)$ & $13(15.7 \%)$ & $01(01.6 \%)$ & 0 & 0 & $01(02.1 \%)$ & \\
\hline \multicolumn{8}{|c|}{ History of ectopic ${ }^{(\mathrm{n}=274)}$} \\
\hline No & $270(98.5 \%)$ & $81(97.6 \%)$ & $62(100 \%)$ & $62(96.9 \%)$ & $17(100 \%)$ & $48(100 \%)$ & \multirow{2}{*}{0.626} \\
\hline Yes & $04(01.5 \%)$ & $02(02.4 \%)$ & 0 & $02(03.1 \%)$ & 0 & 0 & \\
\hline \multicolumn{8}{|c|}{ Chronic illness ${ }^{(\mathrm{n}=272)}$} \\
\hline No & $223(82.0 \%)$ & $64(77.1 \%)$ & $51(82.3 \%)$ & $54(85.7 \%)$ & $13(76.5 \%)$ & $41(87.2 \%)$ & \multirow{2}{*}{0.53} \\
\hline Yes & $49(18.0 \%)$ & $19(22.9 \%)$ & $11(17.7 \%)$ & $09(14.3 \%)$ & $04(23.5 \%)$ & $06(12.8 \%)$ & \\
\hline \multicolumn{8}{|c|}{ Bleeding disorder ${ }^{(\mathrm{n}=273)}$} \\
\hline No & $272(99.6 \%)$ & $83(100 \%)$ & $62(100 \%)$ & $63(98.4 \%)$ & $17(100 \%)$ & $47(100 \%)$ & \multirow{2}{*}{--} \\
\hline Yes & $01(0.4 \%)$ & 0 & 0 & $01(01.6 \%)$ & 0 & 0 & \\
\hline \multicolumn{8}{|c|}{ Drugs leading to bleed ${ }^{(\mathrm{n}=273)}$} \\
\hline None & $262(96.0 \%)$ & $75(90.4 \%)$ & $62(100 \%)$ & $63(98.4 \%)$ & $16(94.1 \%)$ & $46(97.9 \%)$ & \multirow{4}{*}{0.043} \\
\hline Aspirin & $01(0.4 \%)$ & 0 & 0 & $01(01.6 \%)$ & 0 & 0 & \\
\hline Enoxparin & $02(0.7 \%)$ & $02(02.4 \%)$ & 0 & 0 & 0 & 0 & \\
\hline Duphastone & $08(02.9 \%)$ & $06(07.2 \%)$ & 0 & 0 & $01(05.9 \%)$ & $01(02.1 \%)$ & \\
\hline
\end{tabular}

$*$ Results are expressed as Mean \pm Standard deviation, number (percentage) and Median (min-max). $\dagger$ Anova * Kruskal-Wallis test $\ddagger$ Fisher exact test $\psi$ Chi-Square. 
Potential risk factors for vaginal bleeding are shown in table 2. Only one patient, who was diagnosed with incomplete miscarriage, had bleeding disorder and 11 cases were on drugs that could lead to bleeding; 8 of them were diagnosed with threatened miscarriage. $47.4 \%$ of the subjects had previous pelvic surgery and $18 \%$ of them had history of chronic illness (Table 2).

Table 3: Frequency of pregnancy bleeding $(n=274)$.

\begin{tabular}{|c|c|c|c|c|c|c|c|}
\hline \multirow[b]{2}{*}{ Factor } & \multirow[b]{2}{*}{ 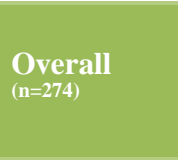 } & \multicolumn{5}{|c|}{ Diagnoses } & \multirow[b]{2}{*}{ P-value* } \\
\hline & & $\begin{array}{l}\text { Threatened } \\
(\mathrm{n}=83)\end{array}$ & $\begin{array}{l}\text { Missed Mis- } \\
\text { carriage } \\
(n=62)\end{array}$ & $\begin{array}{l}\text { Incomplete } \\
\text { Mis-carriage } \\
(n=64)\end{array}$ & $\begin{array}{l}\text { Ectopic } \\
(\mathrm{n}=17)\end{array}$ & $\begin{array}{l}\text { Others } \\
(\mathrm{n}=48)\end{array}$ & \\
\hline \multicolumn{8}{|l|}{ Bleeding volume ${ }^{(\mathrm{n}=266) \S}$} \\
\hline Spotting & $37(13.9 \%)$ & $08(09.8 \%)$ & $13(22.8 \%)$ & $03(04.8 \%)$ & $04(23.5 \%)$ & $09(19.1 \%)$ & \multirow{3}{*}{$<0.001$} \\
\hline Mild & $165(62.0 \%)$ & $67(81.7 \%)$ & $36(63.2 \%)$ & $28(44.4 \%)$ & $11(64.7 \%)$ & $23(48.9 \%)$ & \\
\hline Moderate & $41(15.4 \%)$ & $04(04.9 \%)$ & $04(07.0 \%)$ & $20(31.7 \%)$ & $01(05.9 \%)$ & $12(25.5 \%)$ & \\
\hline Severe & $13(04.9 \%)$ & 0 & $01(01.8 \%)$ & $11(17.5 \%)$ & 0 & $01(02.1 \%)$ & \\
\hline Brownish discharged & $08(03.0 \%)$ & $03(03.7 \%)$ & $03(05.3 \%)$ & 0 & $01(05.9 \%)$ & $01(02.1 \%)$ & \\
\hline Clots & $02(0.8 \%)$ & 0 & 0 & $01(01.6 \%)$ & 0 & $01(02.1 \%)$ & \\
\hline Bleeding duration $^{(\mathrm{n}=262)}$ & $1(0-30)$ & $1(1-7)$ & $2(0-14)$ & $2(1-14)$ & $1(0-7)$ & $1(0-30)$ & $0.069 *$ \\
\hline
\end{tabular}

* Results are expressed as median (min-max) and number (percentage).

Table 4: Frequency of incidence of vaginal bleeding disorders $(\mathbf{n}=\mathbf{2 7 4})$.

\begin{tabular}{|ll|}
\hline Factor & Incidence \\
\hline Diagnoses & $274(37.85 \%)$ \\
\hline Unclassified & $16(02.2 \%)$ \\
\hline Threatened miscarriage & $83(11.5 \%)$ \\
\hline Missed miscarriage & $56(07.7 \%)$ \\
\hline Blighted ovum & $06(0.83 \%)$ \\
\hline Complete miscarriage & $12(01.7 \%)$ \\
\hline Early pregnancy & $04(0.55 \%)$ \\
\hline Incomplete miscarriage & $64(08.8 \%)$ \\
\hline Inevitable pregnancy & $12(01.7 \%)$ \\
\hline Molar pregnancy & $04(0.55 \%)$ \\
\hline Ectopic & $17(02.35 \%)$ \\
\hline * Results are expressed as number (percentage). Total number \\
of new referral during Aug 2011 - May 2012 = 724.
\end{tabular}

Table 3 shows characteristics of vaginal bleeding. The median bleeding duration was one day for all participants and for all diagnoses except for missed miscarriage and incomplete miscarriage that had a median of two days. Regarding bleeding volume, $62 \%$ of patients had mild bleeding, $15.4 \%$ had moderate bleeding, $13.9 \%$ had spotting, and $4.9 \%$ had severe bleeding. Expectedly, 11 of the 13 patients with severe bleeding had diagnosis of incomplete miscarriage. Regarding moderate bleeding, it was present in $4.9 \%$ of patients with threatened miscarriage, $7 \%$ of patients with missed miscarriage, $31.7 \%$ of patients with incomplete miscarriage, and $5.9 \%$ of patients with ectopic pregnancy (Table 3 ).

Table 4 shows incidence of vaginal bleeding for the whole cohort by final diagnosis. The overall incidence of first trimester vaginal bleeding our study cohort was $37.9 \%$. The incidence of threatened miscarriage the highest with rate of $11.5 \%$ followed by incomplete miscarriage with incidence rate of $8.8 \%$ and missed carriage with incidence rate of $7.7 \%$. The lowest detected incidence was for molar pregnancy with incidence rate of $0.55 \%$ (Table 4).

Web-table 1 shows clinical examination and investigations outcomes for the study participants by final diagnosis. $93.8 \%$ of study participants were stable, while $6.2 \%$ had tachycardia. The uterus was palpable in $23.2 \%$. Interestingly the uterus was palpable in $41 \%$ of patients with missed miscarriage. Tenderness was detected only in $5.5 \%$ of the cases. Cervical OS was closed in $52.7 \%$ of the patients, open in $24.1 \%$ of them, while $22 \%$ of them refused to be examined. Patients with incomplete miscarriage had the lowest mean haemoglobin of $10.7 \pm$ SD (1.7) with statistically significant difference between patients by diagnosis $(\mathrm{P}=0.003)$.

\section{DISCUSSION}

This was the first study to assess the incidence of first trimester vaginal bleeding in the KSA. Results are based on the follow up of 724 women who were followed in a retrospective approach at our center. $37.9 \%$ of them (274) of them developed first trimester vaginal bleeding. This rate is higher than reported in a study from England. ${ }^{20}$ In the 550 on-going pregnancies bleeding occurred before the 20th week in $117(21 \%)$, and $67(12 \%)$ ended in miscarriage. It is also higher than reported incidence of $27 \%$, for first vaginal bleeding amongst 4510 participants in an American study. Differences in the methodologies, age range, incidence of infections and other risk factors could justify the wide range of differences in the 
prevalence of first trimester vaginal bleeding. However, international figures indicates that reported rates range between $7 \%$ and $27 \%$, while our rate of $37.9 \%$ is still higher than these figures. ${ }^{17}$

Table 5: Clinical examination outcomes for patients with first trimester vaginal bleeding.

\begin{tabular}{|c|c|c|c|c|c|c|c|}
\hline \multirow[b]{2}{*}{ Factor } & \multirow[b]{2}{*}{ Overall ${ }^{(\mathrm{n}=274)}$} & \multicolumn{5}{|c|}{ Diagnoses } & \multirow[b]{2}{*}{ P-value ${ }^{\ddagger}$} \\
\hline & & $\begin{array}{l}\text { Threatened } \\
(\mathrm{n}=83)\end{array}$ & $\begin{array}{l}\text { Missed mis- } \\
\text { carriage } \\
(n=62)\end{array}$ & $\begin{array}{l}\text { Incomplete } \\
\text { mis-carriage } \\
(n=64)\end{array}$ & $\begin{array}{l}\text { Ectopic } \\
(\mathrm{n}=17)\end{array}$ & $\begin{array}{l}\text { Others } \\
(\mathrm{n}=48)\end{array}$ & \\
\hline \multicolumn{8}{|l|}{ Tachycardia $^{(\mathrm{n}=274)}$} \\
\hline Stable & $257(93.8 \%)$ & $81(97.6 \%)$ & $57(91.9 \%)$ & $57(89.1 \%)$ & $16(94.1 \%)$ & $46(95.8 \%)$ & \multirow{2}{*}{0.226} \\
\hline Tachycardia & $17(06.2 \%)$ & $02(02.4 \%)$ & $05(08.1 \%)$ & $07(10.9 \%)$ & $01(05.9 \%)$ & $02(04.2 \%)$ & \\
\hline \multicolumn{8}{|c|}{ Abdominal examination palpable uterus ${ }^{(\mathrm{n}=150)}$} \\
\hline Not palpable & $115(76.7 \%)$ & $50(80.6 \%)$ & $13(59.1 \%)$ & $32(82.1 \%)$ & $08(100 \%)$ & $12(63.2 \%)$ & \multirow{2}{*}{0.059} \\
\hline Palpable & $35(23.3 \%)$ & $12(19.4 \%)$ & $09(40.9 \%)$ & $07(17.9 \%)$ & 0 & $07(36.8 \%)$ & \\
\hline \multicolumn{8}{|l|}{ Tenderness $(\mathbf{n = 2 7 2 )}$} \\
\hline Not tender & $257(94.5 \%)$ & $82(100 \%)$ & $62(100 \%)$ & $61(95.3 \%)$ & $09(56.3 \%)$ & $43(89.6 \%)$ & \multirow{2}{*}{$<0.001$} \\
\hline Tender & $15(05.5 \%)$ & 0 & 0 & $03(04.7 \%)$ & $07(43.8 \%)$ & $05(10.4 \%)$ & \\
\hline \multicolumn{8}{|l|}{ Fetal heart $^{(\mathrm{n}=104)}$} \\
\hline No & $71(68.3 \%)$ & $22(41.5 \%)$ & $11(100 \%)$ & $23(95.8 \%)$ & $06(100 \%)$ & $09(90.0 \%)$ & \multirow{2}{*}{$<0.001$} \\
\hline Positive & $33(31.7 \%)$ & $31(58.5 \%)$ & 0 & $01(04.2 \%)$ & 0 & $01(10.0 \%)$ & \\
\hline \multicolumn{8}{|c|}{ Cervical OS ${ }^{(\mathrm{n}=224)^{* *}}$} \\
\hline Closed & $118(52.7 \%)$ & $39(54.9 \%)$ & $34(72.3 \%)$ & $19(31.1 \%)$ & $04(30.8 \%)$ & $22(68.8 \%)$ & \multirow{2}{*}{$<0.001$} \\
\hline Open & $54(24.1 \%)$ & $02(02.8 \%)$ & $05(10.6 \%)$ & $38(62.3 \%)$ & 0 & $09(28.1 \%)$ & \\
\hline $\begin{array}{l}\text { Not done/Patient } \\
\text { refused }\end{array}$ & $49(21.9 \%)$ & $30(42.3 \%)$ & $08(17.0 \%)$ & $04(06.6 \%)$ & $06(46.2 \%)$ & $01(03.1 \%)$ & \\
\hline Cervical excitation & $03(01.3 \%)$ & 0 & 0 & 0 & $03(23.1 \%)$ & 0 & \\
\hline \multicolumn{8}{|c|}{ Size of uterus $(n=174)^{* * *}$} \\
\hline Not felt & $102(58.6 \%)$ & $49(74.2 \%)$ & $11(42.3 \%)$ & $22(48.9 \%)$ & $07(50.0 \%)$ & $13(56.5 \%)$ & \multirow{2}{*}{0.003} \\
\hline Bulky & $51(29.3 \%)$ & $12(18.2 \%)$ & $10(38.5 \%)$ & $20(44.4 \%)$ & 0 & $09(39.1 \%)$ & \\
\hline $\begin{array}{l}\text { Not done/patient } \\
\text { refused }\end{array}$ & $21(07.7 \%)$ & $05(07.6 \%)$ & $05(19.2 \%)$ & $03(06.7 \%)$ & $07(50.0 \%)$ & $01(04.3 \%)$ & \\
\hline \multicolumn{8}{|c|}{ Adenexal tenderness ${ }_{(\mathrm{n}=272)}$} \\
\hline No tenderness & $260(95.6 \%)$ & $81(97.6 \%)$ & $62(100 \%)$ & $62(96.9 \%)$ & $09(56.3 \%)$ & $46(97.9 \%)$ & \multirow[b]{2}{*}{$<0.001$} \\
\hline $\begin{array}{l}\text { Positive/cervical } \\
\text { excitation }\end{array}$ & $12(04.4 \%)$ & $02(02.4 \%)$ & 0 & $02(03.1 \%)$ & $07(43.8 \%)$ & $01(02.1 \%)$ & \\
\hline \multicolumn{8}{|c|}{ Pregnancy test $^{(\mathrm{n}=274)^{* *}}$} \\
\hline Negative & $01(0.4 \%)$ & $01(01.2 \%)$ & 0 & 0 & 0 & 0 & \multirow[t]{3}{*}{---} \\
\hline Positive & $205(74.8 \%)$ & $71(85.5 \%)$ & $34(54.8 \%)$ & $49(76.6 \%)$ & $17(100 \%)$ & $34(70.8 \%)$ & \\
\hline Not done & $68(24.8 \%)$ & $11(13.3 \%)$ & $28(45.2 \%)$ & $15(23.4 \%)$ & 0 & $14(29.2 \%)$ & \\
\hline Ultrasound official - & bedside $^{(\mathrm{n}=265)^{* *}}$ & & & & & & \\
\hline No gestational SAC & $29(10.9 \%)$ & $01(01.2 \%)$ & $02(03.3 \%)$ & $06(10.3 \%)$ & $11(68.8 \%)$ & $09(19.1 \%)$ & \\
\hline Yes & $198(74.7 \%)$ & $75(90.4 \%)$ & $50(82.0 \%)$ & $39(67.2 \%)$ & $04(25.0 \%)$ & $30(63.8 \%)$ & $<0.001$ \\
\hline Not done & $38(14.3 \%)$ & $07(08.4 \%)$ & $09(14.8 \%)$ & $13(22.4 \%)$ & $01(06.3 \%)$ & $08(17.0 \%)$ & \\
\hline Fetal pole ${ }^{(n=240)^{* *}}$ & & & & & & & \\
\hline No & $113(47.1 \%)$ & $15(20.0 \%)$ & $31(52.5 \%)$ & $28(57.1 \%)$ & $13(86.7 \%)$ & $26(61.9 \%)$ & \\
\hline Yes & $94(39.2 \%)$ & $55(73.3 \%)$ & $19(32.2 \%)$ & $08(16.3 \%)$ & $01(06.7 \%)$ & $11(26.2 \%)$ & $<0.001$ \\
\hline Not done & $33(13.8 \%)$ & $05(06.7 \%)$ & $09(15.3 \%)$ & $13(26.5 \%)$ & $01(06.7 \%)$ & $05(11.9 \%)$ & \\
\hline Heartbeat ${ }^{(\mathrm{n}=235) * *}$ & & & & & & & \\
\hline No & $163(69.4 \%)$ & $28(38.4 \%)$ & $52(85.2 \%)$ & $36(76.6 \%)$ & $14(100 \%)$ & $33(82.5 \%)$ & \\
\hline Yes & $43(18.3 \%)$ & $40(54.8 \%)$ & 0 & $01(02.1 \%)$ & 0 & $02(05.0 \%)$ & $<0.001$ \\
\hline Not done & $29(12.3 \%)$ & $05(06.8 \%)$ & $09(14.8 \%)$ & $10(21.3 \%)$ & 0 & $05(12.5 \%)$ & \\
\hline Adenexal mess ${ }^{(n=1}$ & & & & & & & \\
\hline No & $126(72.4 \%)$ & $29(85.3 \%)$ & $43(82.7 \%)$ & $28(71.8 \%)$ & $01(05.9 \%)$ & $25(78.1 \%)$ & \\
\hline Yes & $19(10.9 \%)$ & $01(02.9 \%)$ & 0 & $01(02.6 \%)$ & $15(88.2 \%)$ & $02(06.3 \%)$ & $<0.001$ \\
\hline Not done & $29(16.7 \%)$ & $04(11.8 \%)$ & $09(17.3 \%)$ & $10(25.6 \%)$ & $01(05.9 \%)$ & $05(15.6 \%)$ & \\
\hline Free fluid $^{(n=253)^{* *}}$ & & & & & & & \\
\hline No & $209(82.6 \%)$ & $72(92.3 \%)$ & $49(81.7 \%)$ & $73(71.7 \%)$ & $12(75.0 \%)$ & $33(84.6 \%)$ & \\
\hline Yes & $15(05.9 \%)$ & $01(01.3 \%)$ & $02(03.3 \%)$ & $07(11.7 \%)$ & $04(25.0 \%)$ & $01(02.6 \%)$ & $<0.001$ \\
\hline Not done & $29(11.5 \%)$ & $05(06.4 \%)$ & $09(15.0 \%)$ & $10(16.7 \%)$ & 0 & $05(12.8 \%)$ & \\
\hline
\end{tabular}

$*$ Results are expressed as number (percentage). ${ }^{\dagger}$ Anova $*$ Kruskal-Wallis test ${ }^{*}$ Fisher exact test. ${ }^{\psi}$ Chi-Square; $* *$ P-value has been calculated for only available data (Excluded: not done/patient refused/cervical excitation). 
Age is an established risk factor for miscarriage. Studies showed the incidence of spontaneous miscarriage reaches $20 \%$ at the age of 35 years and $40-50 \%$ at the age of 40.Participants in the above study from England were younger than participants in our study, therefore the age difference could justify, at least partially, the above difference in the incidence of first trimester vaginal bleeding.

Threatened miscarriage is the most common complication in the first half of pregnancy. Most of these pregnancies continue to term with or without treatment. In our study, it was the most common cause of vaginal bleeding with incidence of $11.5 \%$. However, this rate is lower than reported in other studies, where the incidence of threatened miscarriage varied from $16(21)$ to $25 \% .^{22}$

Previous studies reported that the incidence of spontaneous (miscarriage) in clinically recognized pregnancies up to 20 gestational weeks varies between $8 \%$ and $20 \%$. Therefore our results of $28 \%$ for incomplete miscarriage missed miscarriage and threatened miscarriage is higher than reported rates. ${ }^{23}$ This difference is attributed to the high rate of incomplete miscarriage $(8.8 \%)$ and complete miscarriage in our study $(7.7 \%)$. It is recommend conduct further research to assess the etiology and justifications for these high reported rates.

The incidence of molar pregnancy in our study of $0.55 \%$ was very high. It is consistent with reports indicating the high incidence of this condition in Asia, when compared with Western countries. Our results is close reported figures from Pakistan $(0.51 \%)$ and much higher than reported in the US with incidence of 1 every 1200 pregnancies. $^{24}$

Regarding the incidence of ectopic pregnancy, our results of $2.35 \%$ are similar to reported in Denmark [16] and higher than reported in England (0.9\%) (Everett).

Patients with ectopic pregnancy presented at an earlier gestation than the remaining participants (mean duration in weeks: $6.4 \pm \mathrm{SD}(1.2), \quad \mathrm{P}<0.001)$. This has been achieved mainly due to enhanced diagnostic capability. ${ }^{25}$

In a study from the USA, 8\% of women with early pregnancy bleeding experienced heaving bleeding, while only $4.9 \%$ of women with early pregnancy bleeding presented with heaving bleeding in our study.

Heavy painful bleeding is associated with higher risk of miscarriage. Expectedly, [painful and heaving bleeding in our study was mainly present in patients with incomplete miscarriage. ${ }^{18}$

The incorporation of early pregnancy ultrasound enabled us to assess fetal viability and verification of gestational dating early during pregnancy. This is one of the advantages for our study. On the other hand, the main limitation of this retrospective cohort study was the incompleteness of data. There was a high proportion of missing data on detailed risk factors for all participants in the cohort study.

The incidence of first trimester vaginal bleeding is high in our center when compared with figures from published literature. The incidence of threatened miscarriage is low, while the incidence of complete or incomplete miscarriage is relatively high when compared with reported figures. Interestingly, similar to detected in other Asian countries, the incidence of molar pregnancy was very high in our study when compared with results from western countries. Further research is recommended to justify the detected high first trimester vaginal bleeding rates and to identify potentials of prevention or improvement of the outcomes of bleeding.

Funding: No funding sources

Conflict of interest: None declared

Ethical approval: The study was approved by the Institutional Ethics Committee of National Guard Health Affairs

\section{REFERENCES}

1. Beischer N, Mackay E, Colditz P: Obstetrics and the Newborn, 3rd Ed. London: WB Sauders 1997.

2. MMWR Current Trends Ectopic Pregnancy: USA, 1990-92 MMWR. 1995;44:46-8.

3. Wittels K, Pelletier A, Brown D, Carmargo Jr. C: United States Emergency Department "Visits for vaginal bleeding during early pregnancy, 1993-2003. Am J Obstet Gynecol. 2008;198:523e1-6.

4. Ananth CV, Savitz DA. Vaginal bleeding and adverse reproductive outcomes: a meta-analysis. Paediatr Perinat Epidemiol. 1994;8:62-78.

5. Williams MA, Mittendorf R, Lieberman E, Monson RR: Adverse infant outcomes associated with firsttrimester vaginal bleeding. Obstet Gynecol. 1991;78:14-8.

6. Berkowitz GS, Harlap S, Beck GJ, Freeman DH, Baras M: Early gestational bleeding and pregnancy outcome: a multivariable analysis. Int $\mathrm{J}$ Epidemiol. 1983;12:165-73.

7. Yang J, Savitz DA, Dole N, Hartmann KE, Herring AH, Olshan AF, Thorp JM: Predictors of vaginal bleeding during the first two trimesters of pregnancy. Paediatr Perinat Epidemiol. 2005;19:276-83.

8. Batzofin JH, Fielding WL, Friedman EA: Effect of vaginal bleeding in early pregnancy on outcome. Obstet Gynecol. 1984;63:515-8.

9. Sipila P, Hartikainen-Sorri AL, Oja H, Von Wendt L: Perinatal outcome of pregnancies complicated by vaginal bleeding. $\mathrm{Br} \mathrm{J}$ Obstet Gynaecol. 1992,99:959-63.

10. Axelsen SM, Henriksen TB, Hedegaard M, Secher NJ: Characteristics of vaginal bleeding during pregnancy. Eur J Obstet Gynecol Reprod Biol. 1995;63:131-4. 
11. Ling FW, Stovall TG. Update on the diagnosis and management of ectopic pregnancy. Advances in obstetrics and gynaecology. Chicago: Mosby Year Book. 1994:55-83.

12. Bukingham K, Fawdry A, Fothergill D. Management of vaginal bleeding presenting to the accident and emergency department. J Accid Emerg Med. 1999;16(2):130-5.

13. Aziz S, Al Wafi B, Al Swadi H. Frequency of ectopic pregnancy in a medical centre, Kingdom of Saudi Arabia. Journal of the Pakistan Medical Association. 2011;61(3):221-40.

14. Eskandar M, Archibong EI, Sadek AA, Sobande AA. Ectopic pregnancy and seasonal variation: a retrospective study from the South Western Region of Saudi Arabia. Bahrain Medical Bulletin. 2002;24(2):63-5.

15. Al-Turki HA. Ectopic pregnancy: prevalence and risk factors in Saudi Arabian Women. Saudi Medical Journals. 2012;339(8):179-82.

16. Nybo-Andersen AM, Wohlfahrt J, Christens P, Olsen J, Melbye M. Maternal age and fetal loss: population based register linkage study. BMJ. 2000;320:170812.

17. Chen BA, Creinin MD. Contemporary management of early pregnancy failure. Clin Obstet Gyneco. 2007;50:67-88.
18. Hasan R, Baird DD, Herring AH, Olshan AF, Jonsson Funk ML, Hartmann KE. Association Between First-Trimester Vaginal Bleeding and Miscarriage. Obstet Gyneco. 2009;114(4):860-7.

19. Fleiss JL, Levin B, Paik MC. Statistical Methods for Rates and Proportions. Third Edition. John Wiley \& Sons. New York 2003.

20. Everett C. Incidence and outcome of bleeding before the 20th week of pregnancy: prospective study from general practice. BMJ. 1997;315:32-4.

21. Cunningham FG, Gant NF, Leveno KJ, Gilstrap LC III, Health JC, Wenstrom KD: 21st ed. Williams obstetrics. New York: McGraw-Hill; 2001:866-67.

22. South J, Naldrelt J. The effect of vaginal bleeding in early pregnancy on the infant born after the 28th week of pregnancy. J Obstet Gynaecol Br Emp. 1973;80:236-41.

23. Regan L, Rai R. Epidemiology and the medical causes of miscarriage. Baillieres Best Pract Res Clin Obstet Gynaecol. 2000;14(5):839-54.

24. Atrash HK, Hogue CJ, Grimes DA. Epidemiology of hydatidiform mole during early gestation. Am J Obstet Gynecol. 1986;154(4):906-9.

25. Shaw JL, Dey SK, Critchley HO, Horne AW. Current knowledge of the aetiology of human tubal ectopic pregnancy. Hum Reprod Update. 2010;16(4):432-44.

Cite this article as: Hassan W, Abu-Helalah M, Salam A, Elhakim A, Bayazeed H, Latif S, et al. Incidence of early pregnancy bleeding in the Eastern region of Saudi Arabia. Int J Reprod Contracept Obstet Gynecol 2016;5:1392-9. 